Western University Scholarship@Western

1996

\title{
Contract Damages and Cooperative Investments
}

Yeon-Koo Che

Tai-Yeong Chung

Follow this and additional works at: https://ir.lib.uwo.ca/economicsresrpt

Part of the Economics Commons

Citation of this paper:

Che, Yeon-Koo, Tai-Yeong Chung. "Contract Damages and Cooperative Investments." Department of Economics Research Reports, 9612. London, ON: Department of Economics, University of Western Ontario (1996). 
ISSN:0318-725X

ISBN:0-7714-1932-5

\title{
RESEARCH REPORT 9612
}

Contract Damages and Cooperative Investments

by

Yeon-Koo Che and Tai-Yeong Chung

EEOHOANCS REFERENCE CENTRE

NOV - 81996

CWNYERSITY DF WESTERN ONTARIO

October 1996

\author{
Department of Economics \\ Social Science Centre \\ University of Western Ontario \\ London, Ontario, Canada \\ N6A $5 \mathrm{C} 2$ \\ econref@sscl.uwo.ca
}




\title{
Contract Damages and Cooperative Investments *
}

\author{
by \\ Yeon-Koo Che ** \\ and \\ Tai-Yeong Chung ***
}

October 1996

* The original version of the paper entitled. "Incomplete Contracts and Cooperative Investments," was presented at Northwestern University, Texas A \& M University, University of Rochester, University of Western Ontario, University of Wisconsin, the Midwest Mathematical Economics Conference at Iowa University, the 7th World Congress at Tokyo, the Canadian Economics Association meeting at Brock University, and the eighth annual conference of Canadian Law and Economics Association at University of Toronto. In particular, the authors thank Ray Deneckere, Rodney Garratt, Don Hausch, Ig Horstmann, Bill Rogerson, Larry Samueison, Kathy Spier, Curt Taylor, and Steve Wiggins for their helpful comments. This paper was completed while the authors were visiting the Yale Law School and the University of Rochester, respectively. The authors gratefully acknowledge their hospitality and financial support.

** Department of Economics, University of Wisconsin-Madison and Yale Law School; Phone: (203) 432-4935, E-mail: yche@facstaff.wisc.edu.

*** Department of Economics, University of Western Ontario, London, Ontario N6A 5C2, Canada; Phone: (519) 679-2111 x5512, E-mail: chung@sscl.uwo.ca. 


\begin{abstract}
This paper studies the effectiveness of alternative contract damages in inducing cooperative investments -- specific investments that generate a direct benefit to the investor's trading partner. We find that, both with and without the possibility of ex post renegotiation, (i) the standard remedy for breach of contracts awarding expectation damages performs poorly in the presence of cooperative investments, (ii) the privately stipulated damages can achieve a better, albeit inefficient, outcome, and (iii) the reliance damages rule performs the best, achieving the fully efficient outcome in the presence of ex post renegotiation. These rankings stand in stark contrast to those found in the existing literature but explain such practices as termination for convenience. investment subsidies, and cost-based reimbursement, often employed in government contracts.
\end{abstract}




\section{Contract Damages and Cooperative Investments}

A principal function of a contract is to coordinate economic activities between two parties who must make relationship-specific investments. It is well known that, when parties cannot write a complete contract, they tend to invest too little in specific assets because of the hold-up problem. ${ }^{1}$ A large literature has been developed to study various aspects of the hold-up problem and possible solutions." The existing literature, however, is limited by its restriction on the nature of specific investments. Largely, it focuses on the specific investments that do not exert direct benefits on the investor's trading partner. For example, a standard scenario portrays a supplier investing to reduce his cost or a buyer investing to increase the benefit from the goods or services provided by the supplier. Investments that generate a direct benefit to the investor's trading partner have received little attention. ${ }^{3}$ Consider, for instance, an investment that a supplier makes to increase the quality of a good or service procured by the buyer. Many R \& D investments that defense contractors undertake for the Department of Defense (DoD), and subcontractors' efforts to customize their components to the special needs of manufacturers are all examples of such investments. ${ }^{4}$ (These investments increase buyers' benefits from trade but do not necessarily reduce sellers' production costs.)

In this paper, such investments that render direct benefits to the investor's trading partner are called "cooperative" investments, while the investments that affect only the investing party's payoff are called "self" investment. Cooperative investments are becoming increasingly common and important, especially with the growing emphasis on the buyer-supplier alliance in industrial purchasing and the increased need for coordination across production stages in modern manufacturing. While both cooperative and self investments are difficult to motivate when they are relationship specific and are not directly contractible, they require qualitatively different contract arrangements, as will be shown in this paper.

Our model features a buyer-seller relationship where a seller makes a cooperative investment that increases a buyer's benefit from trade stochastically. ${ }^{5}$ The investment is specific 
to the relationship, so the investment loses much of its value outside the relationship. The types of contracts we consider are incomplete. In many parts of our paper, the only verifiable information is whether a trade has occurred or not, so a feasible contract specifies two prices: trade price, $p$, and a no-trade price (or damages), $\delta$, that the buyer pays to the seller in the event of trade and no trade, respectively. In some cases, the parties specify only the trade price and, in the event of breach, the court determines damages according to the chosen remedy rule. Alternatively, the parties may specify their own liquidated damages or a damages rule. Our objective is to study how parties induce cooperative investments with such incomplete contracts. Specifically, we characterize the optimal contracts under alternative contract damages:

expectation, liquidated, and reliance damages rules, and examine their performances in terms of investment incentives and trading efficiencies. ${ }^{6}$

The literature on contract damages has addressed the same issues in the context of self investments, and obtained a clear and robust ranking among alternative contract damages. First, the expectation damages rule (ED rule hereafter), which is the default remedy, dominates other legal remedies, and performs reasonably well in various situations (see, for example, Shavell (1980, 1984), Rogerson (1984), Konakayama et al (1986), and Edlin (1996)). By compensating the victim of breach for the anticipated profit, the ED rule forces the breaching party to internalize the loss imposed on his current partner, thus entailing the efficient breaching decision. Further, the breaching party has the right incentive for reliance, although the breached-against party overinvests. Second, if the parties are able to stipulate liquidated damages (LD rule hereafter), they can induce efficient breaching without creating overinvestment (Cooter (1985), Chung (1992) and Spier and Whinston (1995)). The optimal LD contract therefore achieves the efficient outcome, and are better than the standard court-adopted legal remedies. Third, the reliance damages rule (the $\mathrm{RD}$ rule hereafter), which compensates the victim of breach for the cost of reliance, performs worse, since it entails inefficient breaching decision and aggravates the overinvestment problem. Despite the inefficiency, the $\mathrm{RD}$ rule has been frequently used in practice. The existing literature explains the common use of $\mathrm{RD}$ rule by the difficulty of 
implementing the ED rule since reliance damages are easier to assess than expectation damages. In the present article, we provide an alternative explanation for the superiority of $R D$ rule.

With cooperative investments, we find results that are drastically different. First, the ED rule performs very poorly in the presence of cooperative investments, inducing a minimal (zero) cooperative investment. Since the ED rule compensates the victim of breach (the seller in our context) for the anticipated profit. the investor receives the same payoff regardless of the realized gains from trade, so she has no incentive to increase the gains from trade through the cooperative investment.

Second, the optimal LD contract whereby the parties stipulate both $\mathrm{p}$ and $\delta$ is superior to the ED rule but does not lead to the first-best outcome. The LD contract can create incentives for a cooperative investment by rewarding the investor (the seller) in the event of successful trade (i.e., upon the buyer's acceptance of the seller's performance), relative to no trade. The awarding of this "trade prize" to the seller means, however, that the buyer does not face the correct marginal social returns in his trade decision, so there is too little trade in equilibrium. Unlike the case of self investments, therefore, the optimal contract yields an inefficient outcome, which is still better than the outcome under the ED rule.

Third, the RD rule outperforms other legal remedies and even the optimal LD contract. Reliance damages serve as a direct investment subsidy which, along with the contractually specified trade prize, leads to a stronger incentive for the investment while creating fewer trade inefficiencies than the optimal LD contract.

The possibility of ex post renegotiation does not alter these results qualitatively. The ED rule continues to perform poorly, again inducing a minimal cooperative investment. The optimal LD contract performs better. As before, the optimal LD contract creates a wedge between the trade and no-trade prices that exceeds the cost of the seller's performance. In addition to the "prize effect," the wedge leads to an increased probability of renegotiation, which creates additional investment incentives for the seller. It turns out that the optimal contract specifies a big enough wedge between the prices so that trade always occurs through renegotiation. The 
resulting outcome is thus equivalent to the typical Williamson outcome that arises when parties initially choose not to contract but ex post negotiate the terms of trade. Too little cooperative investment is made in this case.

Once again the $\mathrm{RD}$ rule performs the best. More importantly, it yields the first-best outcome. Under the RD rule, the seller can recover the cost of investment as well as part of any renegotiation surplus in the event of breach. This subsidy effect combined with the renegotiation effect is sufficient to overcome the underinvestment problem that arises in the fixed-price contract.

These results, while surprising from the standpoint of the existing literature, explain a number of observed contracting practices when cooperative investments are important. Option contracts, or delivery contingent contracts, are often-observed practices that are consistent with the optimal fixed-price contract that we identify. Moreover, the superiority of the RD rule explains the prevalence of cost-reimbursement types of schemes and other special features of government contracting, which we will discuss more in the text. Most of all, our results underscore the difficulty of inducing cooperative investments through contracting. The limited value of contracting may explain the role of organizational design in situations where cooperative investments are important.

The rest of the paper is organized as follows. Section I illustrates the difficulty of inducing cooperative investments in a simple deterministic model. Section II introduces our main model with stochastic gains from trade. Sections III and IV present our main analyses, without and with the possibility of renegotiation. Section V concludes.

\section{Investment in a deterministic model}

To contrast cooperative investments with self investments, consider a deterministic model in which a buyer and a seller trade a good in the second period. Both parties are risk-neutral. In the first period, the seller makes a cooperative investment, $e \in \Re_{+}$, that increases the buyer's benefit from trade, $v(e)$ (that is, $v(\bullet)$ is increasing), and a self investment, $r \in \Re_{+}$, that reduces her 
own production costs. $c(r)$, (that is. $c(\bullet)$ is decreasing). Assume that $v(\bullet)$ and $-c(\bullet)$ are strictly concave and that $\mathrm{v}(0)>\mathrm{c}(0)$, which makes trade beneficial.

The efficient (first-best) investments maximize

$$
W(e, r) \equiv v(e)-c(r)-e-r
$$

Assume that there exists a unique, strictly positive solution $\left(\mathrm{e}^{*}, \mathrm{r}^{*}\right)$ to this problem.

Suppose that the parties do not initially write a contract and simply bargain ex post to determine terms of trade. Assume that in the bargaining the parties split the surplus with the seller receiving a share $\alpha \in[0,1] .^{7}$ Given investments $e$ and $r$. total gains from trade are $v(e)$ $c(r)$. Since the investments are sunk. the seiler's ex post payoff from the bargaining is $\alpha(v(e)$ $c(r))$. In the first period. the seller picks e and $r$ to maximize

$$
U(e, r)=\alpha[v(e)-c(r)]-e-r .
$$

Unless $\alpha=1$, the investing party does not appropriate full returns from her investments, so she invests too little. This underinvestment result is precisely due to the hold-up problem that has been emphasized in the transaction-costs economics literature.

Next, suppose that the parties initially write a contract whereby the seiler promises to trade the good with the buyer at a fixed price $p$. Assume that the parties prefer to trade at that price. Under the ED rule, the seller is guaranteed her contract profit: $p-c(r)$, regardless of the buyer s breach decision. Hence. in the first period, the seller picks e and $r$ to maximize

$$
U(e, r)=p-c(r)-e-r .
$$

Comparison of (3) and (1) reveals that the seller picks the efficient level of self investment (i.e., $r=r^{*}$ ). The incentives for the cooperative investment are bad. however. Since 
the objective function is strictly decreasing in e. the seller picks zero cooperative investment (i.e.. $\left.\mathrm{e}=0<\mathrm{e}^{*}\right)$. This example illustrates that the nature of investment has important implications for the performance of a contract. For example, if there were only cooperative investment, having no contract would be better than entering into such a simple contract based on the ED rule.

Other remedies may provide a better incentive for cooperative investments. In particular, if the parties can design liquidated damages, the efficient investments can be induced in this simple deterministic model. Consider a contract of the form $\left(\mathrm{p}, \delta_{0}\right)$, where $\mathrm{p}=\mathrm{v}\left(\mathrm{e}^{*}\right)$ and $\delta_{0}=0$, (i.e., the buyer pays nothing to the seller in the event of breach). Given this contract, the buyer will breach if and only if $v(e)-p=v(e)-v\left(e^{*}\right)<-\delta_{0}=0$, or $e<e^{*}$. Knowing that there will be no sale if $e<e^{*}$, the seller will invest at efficient levels $\left(e^{*}, r^{*}\right)\left(\right.$ since $p-c\left(r^{*}\right)-e^{*}-r^{*}=v\left(e^{*}\right)$ $\left.c\left(r^{*}\right)-e^{*}-r^{*}>0\right)$. This contract works because it rewards the seller conditional on the buyer's willingness to trade, and the price is set so that the buyer is willing to trade only when the seller has invested at the efficient levels.

In our main model with stochastic gains from trade, the simple fixed-price contract can no longer implement the efficient investments. Nonetheless, the idea that the buyer's willingness to trade is used as an investment incentive remains important.

\section{The Model}

Our main model builds on the simple buyer-seller relationship introduced in Section I. Again, the seller makes a cooperative investment prior to the trade decision. (As usual, the case where the buyer, rather than the seller, invests is completely symmetric.) The buyer's benefit from trade, $v$, is now a random variable stochastically determined by the amount of the seller's investment, e, measured in dollar expenses. While we assume, for ease of exposition. that the investment is one dimensional, many of our results can be readily extended to the multiinvestment environment. The Appendix discusses such an extension. To focus on cooperative investments, we also assume away any cost-reducing (self) investment. 
Besides the seller's investment, trade also requires seller's performance, whose cost is deterministic and equal to a known constant, $\mathrm{c}>0$. The seller's investment and the buyer's $e x$ post benefit from trade are observable to both parties but not verifiable to a court. Whether a trade occurs or not is verifiable. Thus, a contract can specify a trade price $\mathrm{p}$ and a no-trade price $\delta .^{9}$

The timing of the model, depicted in Figure 1, is as follows. At date 0, the buyer and seller sign a contract that specifies a fixed-price $\mathrm{p}$ to be paid by the buyer when he receives the good from the seller. The contract may also stipulate damages or a damages rule. At date 1, the seller makes a cooperative investment e. At date 2. the buyer's benefit from the seller's performance. $v$, is drawn from $[0, \mathrm{~V}]$ by the distribution function $F(\bullet l e)$. The seller's cost of performance is deterministic and equal to $c$, where $0<\mathrm{c}<\mathrm{V}$. At date 3 , the buyer determines whether to accept or reject the seller's performance. The assumption that the buyer, and not the seller, is the potential breaching party is reasonable ${ }^{10}$ but it is also innocuous: it turns out that, at the optimal contract, the seller prefers not to breach the contract. At date 4, the buyer and the seller's payoffs are determined. In the second part of this paper, the possibility of renegotiation is introduced between date 3 and date 4 . When renegotiation takes place. we assume that the parties' bargaining power is exogenously given, with the seller receiving a share, $\alpha \in[0,1]$, of $e x$ post bargaining surplus."

The following technical assumptions are made throughout the paper.

Assumption $1 . \mathrm{F}(\bullet \bullet)$ is twice continuously differentiable.

Assumption 2. $\mathrm{F}_{\mathrm{e}}(\mathrm{vle})<0, \mathrm{~F}_{\mathrm{ee}}(\mathrm{vle})>0$ for all $\mathrm{v}$ in $(0, \mathrm{~V})$ and for all $\mathrm{e} \geq 0$.

Assumption 3. $\mathrm{F}_{\mathrm{e}}(\mathrm{v} \mid 0)=-\infty$, and $\mathrm{F}_{\mathrm{e}}(\mathrm{v} \mid \infty)=0$ for all $\mathrm{v}$ in $(0, \mathrm{~V})$.

Assumption 2 means that an increase in e moves the distribution in the sense of the firstorder stochastic dominance at a decreasing rate, while Assumption 3 ensures an interior solution. As a benchmark, we first consider the efficient (first-best) outcome. It has two 
components: (i) efficient trade: trade occurs if and only if $\mathrm{v} \geq \mathrm{c}$, and (ii) efficient investment: the level of investment $e^{*}$ maximizes net expected gains from trade, conditional on the efficient trade, or formally

$$
e^{*} \in \operatorname{argmax} W(e) \equiv \int_{\{v \geq c\}}(v-c) d F(v l e)-e .
$$

By Assumption 2 and 3, $\mathrm{e}^{*}$ is finite and strictly positive. Thus, $\mathrm{e}^{*}$ is characterized by the first-order condition:

$$
W^{\prime}\left(e^{*}\right)=-\int_{\{v \geq c\}} F_{e}\left(v l e^{*}\right) d v-1=0
$$

Since $F(v l \bullet)$ is convex, the solution is unique.

It is also useful to consider the situation where the parties do not contract at date 0 , but simply bargain at date 3 to determine the trade price. If the bargaining is efficient, then trade will occur if and only if $v \geq c$. Given that the seller receives a share, $\alpha \in[0,1]$, of ex post bargaining surplus, the seller's ex post payoff from the bargaining is $\alpha(\mathrm{v}-\mathrm{c})$. (The seller's investment $\mathrm{e}$ is already sunk, so it does not affect the bargaining outcome.) At date 1, the seller's expected payoff is

$$
U(e)=\alpha j_{\{v \geq c\}}(v-c) d F(v l e)-e .
$$

The optimal investment is characterized by

$$
U^{\prime}(e)=-\alpha \int_{\{v \geq c\}} F_{e}(v l e) d v-1=0
$$

Comparison of (5) and (7) reveals that the seller underinvests for all $\alpha<1$. As before, the underinvestment is attributed to less than full appropriation of the investment returns. One 
would expect the parties to improve upon this result by writing a contract, albeit incomplete and simple. We turn to this issue next. It turns out that the attractiveness of contracting depends upon the remedy for breach of contract.

\section{Contracting When Renegotiation is Not Possible}

As mentioned in Introduction, our contracts are distinguished by the manner in which the damages $\delta$ is assessed. For now, it is convenient to consider a contracting game with a general contract term $(\mathrm{p}, \delta)$ without being specific about how $\delta$ is determined. Defining a "net trade price" $\mathrm{x} \equiv \mathrm{p}-\delta$, one can use $(\mathrm{x}, \delta)$ to represent the contract term, without loss of generality. As will become clear, the net trade price plays a crucial role in determining the performance of a contract.

We apply backward induction starting with the buyer's breach decision. Given the contract terms, the buyer breaches if and only if $v-p<-\delta$, or $v<x$. For the buyer, the net trade price constitutes the true opportunity cost of accepting the performance, since if he accepts the seller's performance, he pays $\mathrm{p}$ and saves $\delta$. Rationally anticipating the buyer's breach decision, the seller invests e to maximize her expected payoff:

$$
\begin{aligned}
U(e, x) & =I_{\{v<x\}} \delta d F(v \mid e)+\int_{\{v \geq x\}}(p-c) d F(v l e)-e \\
& =(x-c)[1-F(x \mid e)]+\delta-e
\end{aligned}
$$

Trade occurs with probability $[1-F(x \mid e)]$, and when it does, the seller earns additional profit of $(x-c)$. Since the probability of trade is increasing in e, a positive level of cooperative investment can be induced by setting the net profit from trading to be positive, (that is, $x-c>0$ ). When ex post renegotiation is not possible, a positive net profit will imply that the buyer will reject some mutually beneficial trade opportunities. The trade-off between the investment 
incentive and the trading efficiency will be the heart of the contracting problem that will be considered below.

\section{A. Expectation Damages Rule}

The expectation damages rule compensates the victim of breach for the expected profit she would have earned had the contract been performed. ${ }^{12}$ We study the ED rule for two reasons. First, the ED rule has been used as a default remedy for breach of contract, so if a contract does not specify remedies for breach, the courts use the rule to compensate the victim of breach. Second, the existing literature shows that the ED rule performs reasonably well when cooperative investment is not important, as mentioned in the introduction. By contrast, the ED rule fails to provide an incentive for cooperative investments, as is shown below.

In our setting the ED rule sets $\delta=p-c$, or $x=c$. Given the ED rule, the trade decision is efficient since the buyer breaches if and only if $v<c{ }^{13}$ Substituting $x=c$ into (8) yields the seller's expected payoff:

$$
\mathrm{UE}^{\mathrm{E}}(\mathrm{e}) \equiv \mathrm{p}-\mathrm{c}-\mathrm{e}
$$

Clearly, a zero investment is the optimal choice for the seller. ${ }^{14}$ The simple intuition is that the ED rule does not reward the seller based on the very important signal for the investment performance, namely the buyer's willingness to trade. Insulated from the buyer's gains to trade, the seller has no incentive for the cooperative investment.

The social surplus under the ED rule is

$$
W^{E} \equiv W(0)=\int_{\{v \geq c\}}(v-c) d F(v \mid 0)
$$

Because of the poor investment incentive, $W^{E}<W\left(e^{*}\right)$. 
PROPOSITION 1: The ED rule induces the efficient trade decision but zero cooperative investment.

Since the ED rule cannot provide an incentive for a cooperative investment, parties to a contract will have an incentive to choose damages differently. We turn to this issue in the next section.

\section{B. Liquidated Damages Rule}

Under the liquidated damages (LD) rule, the parties specify $(p, \delta)$, or equivalently $(x, \delta)$. Given $\mathrm{x}$, the buyer and the seller's joint expected surplus is

$$
W(e, x) \equiv \int_{\{v \geq x\}}(v-c) d F(v l e)-e,
$$

where $\mathrm{e}$ is chosen by the seller to maximize her own expected payoff,

$$
U^{L}(e, x) \equiv U(e, x)=(x-c)[1-F(x l e)]+\delta-e .
$$

It is clear from (10) and (11) that $x$ determines both trade and investment decisions. while $\delta$ affects only the distribution of the surplus between the two parties.

The contracting problem at date 0 can be formally written as

$$
\begin{gathered}
\max _{x . e} W(e, x) \\
\text { subject to } e \in \underset{\tilde{e} \geq 0}{\operatorname{argmax}} U^{L}(\tilde{e}, x)
\end{gathered}
$$

The optimal investment $e^{L}(x)$, is characterized implicitly by

$$
U_{e}^{L}(e, x)=-(x-c) F_{e}(x \mid e)-1=0,
$$


for all $x \geq c$, and $\mathrm{e}^{\mathrm{L}}(\mathrm{x})=0$ for all $\mathrm{x}<\mathrm{c}$. By Assumptions 2 and $3, \mathrm{e}^{\mathrm{L}}(\mathrm{x})$ is well defined and unique for all $x \geq 0$. We argue that the optimal net trade price. $x^{L}$, is strictly greater than $c$. To see this, observe first that setting $x=c$ leads to the efficient trade decision but zero cooperative investment (i.e., $e^{L}(c)=0$ ) -- the outcome under the ED rule. Lowering $x$ below $c$ does not help here since the level of investment will still be zero while the trade decision will become inefficient. Next, raise $x$ above $c$ by a small amount. Then, by Assumption $3, e^{L}(x)$ will become strictly positive. Consequently, the joint surplus rises stochastically, and its impact is not negligible. Raising $x$ above $c$ creates trade inefficiencies, as the buyer rejects some mutually beneficial trade opportunities, but the latter effect is negligible since $W_{X}(e, x)=0$ at $x=c$ from (10). This argument shows that $x^{L}>c .{ }^{15}$ It also implies that the optimal LD contract outperforms the ED rule.

One can interpret the wedge, $x^{\mathrm{L}}-\mathrm{c}$, as the "prize" awarded to the seller in the event of trade. Since trade occurs when the buyer receives sufficient benefits from the seller's performance, the prize for trade induces the seller to internalize part of the gains to trade. A disadvantage of instituting a prize for trade is, however, that a mutually beneficial trade may not occur. This is the case if $c<v<x^{L}$. The higher the prize is, the larger the trade inefficiencies are. The optimal net trade price, $x^{L}$, is therefore chosen to balance the investment incentive and the trade inefficiencies. ${ }^{16}$

The equilibrium social surplus under liquidated damages is obtained as

$$
\mathrm{W}^{\mathrm{L}} \equiv \max _{\mathrm{x}} \mathrm{W}\left(\mathrm{e}^{\mathrm{L}}(\mathrm{x}), \mathrm{x}\right)
$$

PROPOSITION 2: The optimal LD contract is characterized by a positive wedge between the net price $x^{L}$ and the seller's cost $c$. The contract cannot implement the efficient outcome, but it leads to a more efficient outcome than the ED rule does. 
That $x^{L}$ completely determines the performance of the contract implies that $\delta$ can be set at zero, without loss of generality. ${ }^{17}$ One can then interpret the optimal contract as an option contract which gives the buyer an option to accept the seller's performance at date 4 at a predetermined price $\mathrm{x}^{\mathrm{L}}$ or to refuse the performance at no penalty. Such an option contract is common, as exemplified by "delivery-contingent contracts" and "purchase upon approval." For instance, advertising agencies often must develop an acceptable pilot campaign before they are paid in full. Real estate agents and other types of brokers typically are not paid until they discover an acceptable match between buyer and seller (see Taylor [1991]). One can also interpret the defense profit regulation in the same light. Defense contractors often earn regulated profits when the Department of Defense selects them as suppliers of weapons systems. The prospect of a profitable contractual relationship serves as a prize that induces firms to exert innovation efforts which are often difficult to motivate otherwise (Lichtenberg [1988], Rogerson [1989]).

\section{Reliance Damages Rule}

Under the $\mathrm{RD}$ rule, the breaching party must reimburse the victim of breach for all nonrecoverable reliance expenses -- expenditure on the specific investment in our context. ${ }^{18}$ In practice, the ED rule is often very difficult to implement because of the measurement problem, so the $R D$ rule has been used as a more practical substitute for the ED rule. To enforce the RD rule, a court must be able to measure, with reasonable certainty, the amount of expenditure actually incurred by the seller. Hence, the RD rule requires the additional information to be verifiable. ${ }^{19}$ Two points are worth noting, however. First, this requirement is not unreasonable in many circumstances. For instance, accounting data and expert testimonies often provide good estimates of the investment expenses. Indeed, the measurement problem is often severer with the expectation damages. ${ }^{20}$ Second, the use of additional information does not guarantee a better performance, when the information is not properly incorporated. Indeed, it is well-known that the $\mathrm{RD}$ rule performs poorly relative to the ED rule in the case of the self investments (Shavell 
[1980]; Rogerson [1984])..$^{21}$ By contrast, in the presence of a cooperative investment, the RD rule performs better than the optimal fixed-price contract, let alone the ED rule, as shown below. Individual parties may write contracts that use the verifiable information better than the $\mathrm{RD}$ rule allows them to. ${ }^{22}$ Nevertheless, the $\mathrm{RD}$ rule, whether it is chosen by a court or privately stipulated by the parties, represents an easy way to incorporate the information. Our interest in the $\mathrm{RD}$ rule lies in its common use as a remedy. The $\mathrm{RD}$ rule is practically the standard remedy in government contracts. The so-called "Termination for Convenience" clause gives the government the broad right to terminate a contract without cause and limits the contractor's recovery to costs incurred, profit on work done and the costs of preparing the termination settlement proposal..$^{23}$ Recovery of anticipated profit is precluded (Cibinic and Nash [1985], Nash and Cibinic [1980])..$^{24}$

Under the RD rule, $\delta=e$ and $x=p-e$. Substituting these into (8) yields the seller's expected payoff function under the RD rule:

$$
U^{R}(e, p-e)=(p-e-c)[1-F(p-e l e)]
$$

We assume that $U^{R}(e, p-e)$ is strictly quasi-concave in $e$ for all $p$, which ensures that there exists a unique equilibrium investment level. As will be shown below, the equilibrium investment level is zero if $\mathrm{p} \leq \mathrm{c}$. For any interior solution, it is convenient to describe the firstorder condition using $\mathrm{x}$ :

$$
U_{e}^{R}(e, x)=-(x-c) F_{e}(x l e)+\left[(x-c) F_{v}(x l e)+F(x \mid e)\right]-1=0 .
$$

If $p \leq c$, then $x=p-e \leq c$ for all $e \geq 0$, which implies that the left-hand side of (15) is strictly negative. Therefore, the optimal investment is zero. Now consider $p>c$. Then, for a sufficiently small $e, x>c$. For such an $e$, the left-hand side of (15) is positive, by Assumption 3. Therefore, the equilibrium investment level under the $R D$ rule is positive if $p>c$. While $x$ is not 
exogenous, it is convenient, for comparison with the other contractual arrangements, to treat it as such. Let $e^{R}(x)$ denote the set of e's that satisfy $(15)$ for $x>c$ and $e^{R}(x) \equiv\{0\}$ for $x \leq c$. 25 Then, any $e \in e^{R}(x)$ can be induced by $p=x+e$. The two parties' contracting problem is characterized as

$$
\max _{x} W^{R}(x) \equiv \max _{e \in e^{R}(x)} W(e, x)
$$

We label the optimal net price and the resulting joint surplus $x^{R}$ and $W^{R}$, respectively.

Since $e^{R}(x)=0$ for $x \leq c$ and $e^{R}(x)>0$ for $x>c$, the argument in the previous section can be used to show that the optimal net trade price. $x^{R}$. is strictly greater than $c$. We next observe that, compared with (12) (under the liquidated damages), (15) has additional terms (inside the brackets) which are positive for $\mathrm{x}>\mathrm{c}$. The second term in the brackets represents a subsidy effect: for each dollar spent for reliance, the seller receives a dollar back whenever the buyer breaches, which occurs with probability $F(x \mid e)$. The first term in the brackets represents the marginal increase in the probability of earning $(x-c)$, which results from the shifting of the threshold value, $x=p-e$, when e increases slightly. The presence of these additional terms means that the seller has a stronger incentive for investment under the RD rule than under the $L D$ rule, given the same $x$. Put differently, the RD rule can induce the same level of cooperative investment as the optimal LD contract, with a smaller $\mathrm{x}-\mathrm{c}$, or a smaller degree of trading inefficiencies.

The following proposition formally shows that the $\mathrm{RD}$ rule induces a more efficient outcome than the optimal LD contract.

PROPOSITION 3: The RD rule cannot implement the efficient outcome, but it leads to a more efficient outcome than does the optimal contract under the privately-stipulated damages.

PROOF: 
Let $e^{L} \equiv e^{L}\left(x^{L}\right)$ and $\Psi(x) \equiv-(x-c) F_{e}\left(x \mid e^{L}\right)+\left[(x-c) F_{V}\left(x \mid e^{L}\right)+F\left(x \mid e^{L}\right)\right]-1$.

Now, note that $\Psi\left(x^{L}\right)=-\left(x^{L}-c\right) F_{e}\left(x^{L} l e^{L}\right)+\left[\left(x^{L}-c\right) F_{v}\left(x^{L} l e^{L}\right)+F\left(x^{L} l e^{L}\right)\right]-1>-\left(x^{L}-c\right) F_{e}\left(x^{L} l e^{L}\right)$ $-1=0$, and that $\Psi(\mathrm{c})<0$. Since $\Psi(\mathrm{x})$ is continuous in $\mathrm{x}$, by the intermediate value theorem, there exists $x^{0} \in\left(c, x^{L}\right)$ such that $\Psi\left(x^{0}\right)=0$. Since $U_{e}^{R}\left(e^{S}, x^{0}\right)=\Psi\left(x^{0}\right)=0, e^{L} \in e^{R}\left(x^{0}\right)$. That is, the same investment level, $e^{s}$, is induced under the $R D$ rule by $x^{0}$, or more precisely by $p=x^{0}+$ $e^{L}$. Since $c<x^{0}<x^{L}$, inefficient breach occurs less frequently under the $R D$ rule than under the privately-stipulated damages. Hence, $W^{R}\left(x^{0}\right)>W^{L}$. Since $W^{R} \geq W^{R}\left(x^{0}\right)$, the $R D$ rule leads to a more efficient outcome than does the optimal fixed-price contract. Q.E.D.

The above result stands in stark contrast to the existing literature that finds the RD rule inferior to the ED rule, let alone the optimal LD contract (Shavell [1980] and Rogerson [1984]). With the cooperative investment, the $\mathrm{RD}$ rule outperforms the other contract damages.

The superior performance of the $\mathrm{RD}$ rule provides a rationale for a number of observed practices, however. The termination for convenience clause makes the RD rule virtually the standard remedy for all government contracts in the U.S., as mentioned above. A similar arrangement can be found in a canceled helicopter deal in Canada. The contract calls for the government to reimburse suppliers for work already done, inventory accumulated, and all reasonable costs associated with their involvement in the program. ${ }^{26}$ Our result justifies the use of termination for convenience or a similar arrangement, based on their superior incentives for cooperative investment. In some $\mathrm{R} \& \mathrm{D}$ procurements, the government has even paid some investment expenses that were incurred independently by firms. A case in point is the DoD's Independent Research and Development (IR\&D) program, whereby the DoD reimburses a certain fraction of the defense contractors' IR\&D expenditures (Lichtenberg [1988], Rogerson [1994]). This type of direct subsidy can encourage cooperative investment by lowering the cost of investment. 
Even with the investment subsidy created by the $\mathrm{RD}$ rule or a similar contract clause, the "prize for trade" intuition is still important since $x^{R}>c$. The subsidy effect augments the prize effect in providing incentives for cooperative investment. If the size of the prize is large enough, the parties may require only a partial reimbursement of the investment cost, as in the DoD's IR\&D program.

\section{Contracting When Renegotiation is Possible}

After the parties observe a realization of the buyer's benefit, it may be mutually beneficial to renegotiate the initial contract. We assume in this section that the parties can renegotiate $e x$ post in a mutually beneficial way. The possibility of renegotiation alters our analysis in an important way. Because the parties renegotiate under complete information, it is reasonable to assume that bargaining is efficient. Given this assumption, any ex post inefficiencies disappear, regardless of the underlying contract remedy.

Formally, the renegotiation can occur after the buyer's breach decision (see Figure 1). ${ }^{27}$ If the buyer's decision is not efficient, the renegotiation process can reverse this decision, and the buyer and seller split any resulting surplus at $1-\alpha$ and $\alpha$. The buyer's decision to breach the initial contract depends on the anticipated bargaining outcome. Suppose first that the buyer honors the contract (i.e., accepts the seller's performance). If trade is efficient, no renegotiation occurs, and the buyer receives $v-p$. If not $(v<c)$, renegoiation occurs, and the buyer receives additional surplus of $(1-\alpha)(c-v)$. Combining the two cases, the buyer's payoff of honoring the contract is:

$$
v-p+(1-\alpha) \max \{c-v, 0\}
$$

(Note that renegotiation occurs only when $c>v$.) Using the symmetric argument, the buyer's payoff of rejecting the performance is obtained as: 


$$
-\delta+(1-\alpha) \max \{v-c, 0\}
$$

(Note that renegotiation occurs when $v>c$ in this case.)

If $\mathrm{v}<\mathrm{c}$, then $\delta \leq(\mathrm{p}-\mathrm{c})$, or $\mathrm{x} \geq \mathrm{c}$, so (18) is always greater than (17). The buyer therefore breaches in this case. If $v \geq c$, the buyer breaches if (18) is greater than (17), or $v-p<-\delta+(1-$ $\alpha)(v-c)$. Therefore, the buyer breaches if and only if $v$ is less than a threshold value, $\hat{v}(x)$ :

$$
\hat{v}(x) \equiv \min \left\{\frac{x-c}{\alpha}+c, V\right\}{ }^{28}
$$

When $c \leq v<\hat{v}(x)$, the buyer breaches initially. Since breaching is inefficient in this case, however, there will be a renegotiation. The seller's ex post payoff is $\mathrm{p}-\mathrm{c}$ if $\mathrm{v}>\hat{\mathrm{v}}(\mathrm{x})$, and $\delta+\alpha$ $\max \{v-c, 0\}$ if $v \leq \hat{v}(x)$. The seller's expected net payoff is then

$$
\begin{aligned}
\mathrm{U}(e, x) & =\int_{\{v<\vartheta(x)\}}[\delta+\alpha \max \{v-c, 0\}] \mathrm{dF}(v l e)+\int_{\{v \geq \vartheta(x)\}}(p-c) d F(v l e)-e \\
& =(x-c)[1-F(v(x) l e)]+\alpha \int_{\{c<v<\uparrow(x)\}}(v-c) d F(v l e)+\delta-e
\end{aligned}
$$

Compared to the case of no-renegotiation, the threshold value for breach is changed from $\mathrm{x}$ in (8) to $\hat{v}(\mathrm{x})$ in (20). The first-term in the right-hand side of (20) is the expected net profit from trade, as before. The second term, $\alpha \int_{\{c<v<\vartheta(x)\}}(v-c) d F(v l e)$ is new here and it represents the seller's share of the surplus from renegotiation. It is strictly positive if and only if $x>c$. (Note that $\hat{v}(x)>c$ if and only if $x>c$.)

If a contract $(x, \delta)$ induces the seller to invest $e$, then the joint expected surplus is given by

$$
W(e) \equiv \int_{\{v \geq x\}}(v-c) d F(v \mid e)-e
$$


(Recall that the trade decision is efficient because of the renegotiation.) The contract terms themselves cannot directly influence the joint surplus, although the terms can indirectly influence it through the seller's investment.

\section{A. Expectation Damages Rule}

With the ED rule, we have $x^{E}=c$, and thus, $\hat{v}\left(x^{E}\right)=c$. The trade decision is efficient, so renegotiation never occurs. As in the case of no-renegotiation, the seller receives $\mathrm{p}-\mathrm{c}-\mathrm{e}$, regardless of the realized gains from trade. Therefore, the previous results continue to hold:

under the ED rule, the seller makes zero investment and the social surplus is given by $\mathrm{W}^{\mathrm{E}}(0)=$ $\int_{\{v \geq c\}}(v-c) d F(v \mid 0)$.

PROPOSITION 4: The ED rule induces the efficient trade decision but zero cooperative investment.

\section{B. Liquidated Damages Rule}

Suppose that the parties specify both $\mathrm{p}$ and $\delta$ in their initial contract. Again, it is convenient to focus on $(x, \delta)$. At date 0 , the parties specify $(x, \delta)$ so that

$$
\begin{gathered}
\max _{x, e} W(e) \\
\text { subject to } e \in \underset{\tilde{e} \geq 0}{\operatorname{argmax}} U^{L}(\tilde{e}, x)
\end{gathered}
$$

where the seller's expected payoff, $U^{L}(e, x)$, is precisely $U(e, x)$ defined in (20). That is,

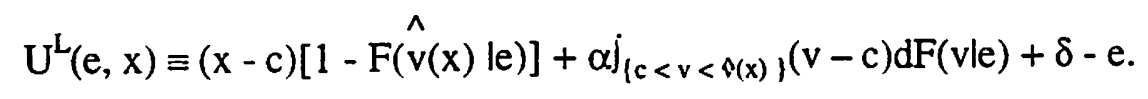

When ex post renegotiation is possible, setting $\mathrm{x}>\mathrm{c}$ can create incentives for the investment in two different ways. The first is the "prize effect": $(x-c)$ constitutes a prize for 
trade that motivates the seller to invest (the first-term in (22)). The second is what we call a "renegotiation effect": the wedge between $x$ and $c$ creates the possibility of inefficient breach that leads to a renegotiation, from which the seller internalizes a fraction of the net trade surplus (the second-term in (22)). The renegotiation effect offsets the prize effect to some extent. As mentioned above, the seller receives a prize $x-c$ if $v^{3} \hat{v}(x)$, but she also receives $\alpha(v-c)$ if $v$ $\hat{\langle v}(x)$. At $v=\hat{v}(x)$, the two quantities are exactly the same since the buyer is indifferent between breaching and not breaching, which implies that the seller receives the same payoff too. Thus, the seller has no incentive to increase the probability that $v$ exceeds $\hat{v}(x)$. The net effect can be seen by collecting the terms of (22) and integrating it by parts.

$$
\begin{aligned}
& \left.U^{L}(e, x)=(x-c)+(c-x) \hat{F}(\hat{v}(x) l e)+\alpha \hat{[v}(x)-c\right] \hat{F}(\hat{v}(x) l e) \\
& -\alpha \int_{\{c<v<v(x)\}} F(v \mid e) d v+\delta-e . \\
& =(x-c)+\alpha\left[\hat{v}(x)-\left\{\frac{x-c}{\alpha}+c\right\}\right] \hat{F}(v(x) l e)-\alpha \int_{\{c<v<\vartheta(x))} F(v l e) d v+\delta-e .
\end{aligned}
$$

The second term in the right-hand side of (23) vanishes if $\frac{x-c}{\alpha}+c \leq V$ from (19).

Otherwise, $\hat{v}(x)=V$, and thus, the second term is independent of e because $F(V \mid \bullet)=1$. Since the third term in (23) is increasing in e, the total combined effect of both methods is positive when $\mathrm{x}$ $>$ c. The seller's optimal investment, $e^{L}(x)$, is characterized by

$$
U_{\mathrm{e}}^{L}(e, x)=-\alpha f_{\{c<v<\uparrow(x)\}} F_{e}(v l e) d v-1=0
$$

for all $x>c$. (Clearly, $e^{L}(x)=0$ if $x \leq c$.) The optimal investment is unique since $F(v \mid \bullet)$ is convex for all $v$ from Assumption 2. Since $\hat{v}(x)$ is increasing for $x<\alpha V+(1-\alpha) c$ and constant for $x \geq \alpha V+(1-\alpha) c, e^{L}(x)$ is increasing for $x<\alpha V+(1-\alpha) c$ and constant for $x \geq \alpha V+(1-\alpha) c .^{29}$ This feature deserves an explanation. In (23), the seller internalizes a fraction of the gains from trade only if the parties renegotiate the initial contract following the buyer's decision to breach 
inefficiently. Therefore, the seller's increased exposure to renegotiation increases her incentive for the investment. The parties raise the possibility of renegotiation by raising $\mathrm{x}$ since it increases the probability that the buyer' breaches initially.

Comparing (24) with (5) reveals that $\mathrm{e}^{\mathrm{L}}(\mathrm{x})<(\leq) \mathrm{e}^{*}$ for any $\mathrm{x}$ and $\alpha<(\leq) 1$. Since the joint expected payoff is increasing in $\mathrm{e}$ for all $\mathrm{e}<\mathrm{e}^{*}$, the optimal $\mathrm{x}$ is the one that maximizes $e^{L}(x)$. The optimal net trade price, $x^{L}$, is any $x$ that is greater than or equal to $\alpha V+(1-\alpha) c$, which guarantees $\hat{v}\left(x^{L}\right)=V$. With $x^{L}$, the buyer always breaches, and then the parties renegotiate to ensure that a trade occurs whenever it is efficient. For any $\alpha$, the seller's optimal investment, $e^{\mathrm{L}} \equiv e^{\mathrm{L}}\left(\mathrm{x}^{\mathrm{L}}\right)$, is characterized by

$$
U_{e}^{L}\left(e^{L}, x^{L}\right)=-\alpha \int_{\{c<v\}} F_{e}\left(v l e^{L}\right) d v-1=0
$$

The joint expected surplus at the optimal stipulated damages is given by $W^{L} \equiv W\left(e^{L}\right)$.

Several observations can be made. First, the optimal fixed-price contract yields underinvestment unless the seller has the entire bargaining power. ${ }^{30}$ The second and more interesting observation is that (25) coincides with (7), the first-order condition when the parties do not sign an initial contract. That is, the optımal fixed-price contract yields an outcome that the parties could have achieved without an initial contract at all! Even without a contract, a voluntary renegotiation between the parties can provide some incentives for cooperative investments since the seller receives a positive share of the bargaining surplus. When renegotiation is possible, the optimal fixed-price contract fails to create any additional incentive. This irrelevance of contracting is novel with the cooperative investment. As is well-known, with self investments, a simple fixed-price contract (known as "efficient expectation damages") can generate an efficient outcome whereas no contracting yields the Williamson type of underinvestment. Finally, if parties do write an contract, the resulting equilibrium has the appearance of the classical hold-up. Recall that the optimal contract price is so high that the buyer initially refuses to accept the seller's performance, regardless of his valuation. The buyer's 
refusal triggers a renegotiation that lowers the price downward to a level that ensures an efficient trade decision. What appears to be a hold-up here is in fact a part of implementation of the optimal contract. Our results are summarized in the following proposition.

PROPOSITION 5: Underinvestment occurs under the optimal LD contract, unless the seller has the entire bargaining power in the renegotiation. The optimal contract induces the buyer to breach the contract with probability one, which is subsequently renegotiated whenever trade is efficient. Contracting is irrelevant in the sense that the parties can achieve the outcome of the optimal fixed-price contract by writing no contract.

Proposition 5 suggests an interesting observation on the value of renegotiation. With self investments, an LD contract can implement the first-best outcome, regardless of the possibility of renegotiation. In that case, therefore, the parties' ability to renegotiate the original contract has no value. With cooperative investments, the value of renegotiation depends on the seller's (investing party's) share, $\alpha$, of the bargaining surplus. If $\alpha$ is close to 1 , then the outcome under renegotiation is nearly efficient, so the ability to renegotiate is valuable. If $\alpha$ is close to 0 , the outcome under renegotiation is strictly worse. ${ }^{31}$ Therefore, the parties will be better off if they can commit not to renegotiate the original contract, in this case.

\section{Reliance Damages Rule}

If the seller can be reimbursed at least a fraction of investment expenditure following the buyer's breach, it may be possible to mitigate the underinvestment problem observed in the previous section. Not only does such reimbursement improve the incentive for cooperative investment, it can be shown to induce the first-best outcome.

The net trade price, $\mathrm{x}$, is equal to $\mathrm{p}$ - e under the $\mathrm{RD}$ rule. It is again convenient, for comparison with the other cases, to treat $x$, rather than $\mathrm{p}$, as the main choice variable. Any $\mathrm{x}$ can be implemented by an appropriately chosen contract price p. Again, the buyer breaches if and 
only if $v<\hat{v}(x)$ (defined in (19)), and a renegotiation corrects inefficient breaches. The seller's expected payoff is obtained by substituting $\delta=e$ into (23):

$$
U^{R}(e, x)=(x-c)+\alpha\left[\hat{v}(x)-\left(\frac{x-c}{\alpha}+c\right)\right] \hat{F}(\hat{v}(x) l e)-\alpha \int_{\{c<v<\rho(x)\}} F(v l e) d v
$$

Using $\mathrm{x}=\mathrm{p}-\mathrm{e}$, the first-order condition for the seller's investment decision is obtained as

$$
U_{e}^{R}(e, x)=\hat{F}(v(x) l e)-\alpha \int_{\{c<v<\vartheta(x)\}} F_{e}(v l e) d v-1=0 .
$$

Again, if $x \leq c$, then $\hat{v}(x) \leq c$. so the left-hand side of (27) is non-positive. Thus, any equilibrium with $x \leq c$ entails zero investment. Since $U^{R}(e, p-e)$ is strictly concave in $e,{ }^{32}$ there exists a unique optimal investment level for the seller for any $p \geq c$. We let $e^{R}(x)$ denote the e that satisfies (27) for $x>c$ and $e^{R}(x) \equiv 0$ for $x \leq c .^{33}$ As before, $e^{R}(x)$ can be implemented by setting $p$ $=x+e^{R}(x)$ because of the strict concavity of $U^{R}(e, p-e)$ in e. Therefore, we can simply focus on $\mathrm{e}^{\mathrm{R}}(\mathrm{x})$ as an equilibrium investment. At date 0 , the parties choose $\mathrm{x}$ (or a corresponding $\mathrm{p}$ ) to maximize their joint expected surplus. Their maximized surplus is labeled $W^{R} \equiv \max _{x} W\left(e^{R}(x)\right)$.

The first two terms in (27) can be explained as follows. The second term, which also appears in the corresponding first-order condition for an LD contract, accounts for the net renegotiation effect. (As before, the prize effect is completely offset at the margin.) The first term accounts for the subsidy effect. When $v<x$, the buyer breaches (and no renegotiation follows), and the seller gets reimbursement of investment expenses as damages. When $\mathrm{x} \leq \mathrm{v} \leq$ $\wedge$ $\hat{v}(x)$, renegotiation reverses the buyer's breach, but the seller still gets the subsidy indirectly through the improved status quo payoff. Consequently, the subsidy effect arises with probability $\hat{F}(v(x) l e)$. The presence of the subsidy effect implies that the $R D$ rule creates a stronger incentive for cooperative investment than the optimal LD contract. In fact, the RD rule implements the first-best outcome, as shown in the next proposition. 
PROPOSITION 6: Under the reliance damages rule with the possibility of renegotiation, there exists a contract, specifying p, that implements the first-best outcome. At the optimal contract, the buver initially defaults more often than under the expectation damages rule, but less often than under the optimal LD contract.

\section{PROOF:}

Define a function of $x$,

$$
\Phi(x) \equiv F\left(\hat{v}(x) l e^{*}\right)-\alpha \int_{\{c<v<\theta(x)\}} F_{e}\left(v l e^{*}\right) d v-1,
$$

where $\mathrm{e}^{*}$ is the efficient investment level defined in (5). Notice that $\Phi(\bullet)$ is continuous, increasing, $\Phi(\mathrm{c})<0$, and $\Phi(\alpha \mathrm{V}+(1-\alpha) \mathrm{c})>0$. It thus follows that there exists $\mathrm{x}^{\mathrm{R}} \in(\mathrm{c}, \alpha \mathrm{V}+$ $(1-\alpha) c)$ such that $\Phi\left(x^{R}\right)=0$. Then, $e^{*}=e^{R}\left(x^{R}\right)$ since $U_{e} e^{2}\left(e^{*}, x^{R}\right)=\Phi\left(x^{R}\right)=0$ and $U_{e}^{R}\left(\bullet, x^{R}\right)$ is decreasing. As noted above, setting $\mathrm{p}^{*}=\mathrm{x}^{\mathrm{R}}+\mathrm{e}^{*}$ induces $\mathrm{e}^{*}$. The second statement immediately follows from the fact that $x^{R} \in(c, \alpha V+(1-\alpha) c)$. Q.E.D.

This proposition reconfirms the superior performance of cost-reimbursement types of contracting arrangements, such as termination for convenience and investment subsidy programs, and explains their common use when cooperative investments are important. As in the case of the optimal-fixed price contract, the contracting equilibrium has the appearance of the hold-up since the originally high contract price is negotiated downward after the investment takes place. The hold-up phenomenon is often a result of parties' inability to write a complete contract, and it typically yields underinvestment. Interestingly, the appearance of a hold-up here serves to achieve the efficient outcome. 


\section{Conclusion}

This paper has studied how parties to a contract can induce cooperative investments through an incomplete contract. The key element of our study has been to figure out how a contract can be designed to reflect the gains from trade in the investor's payoff. When the investment is cooperative, a trader's willingness to trade can be an important (often the only), verifiable signal for the investment. Therefore, contracts that reward a prize to the investor whenever her partner shows high willingness to trade tend to perform better than the contracts that do not. For example, the ED rule performs very poorly since it fails to implement such a prize. By contrast, the LD rule performs better since it can implement such a prize. Finally, the use of the RD rule, or a similar investment subsidy, provides additional incentives for cooperative investments and can significantly improve the performance of contracts. In particular, it leads to the first-best outcome if ex post renegotiation is possible.

In practice, most of specific investments have the elements of both self and cooperative investments. In this mixed environment, the performance of the contract damages will depend on the relative importance of each element, so the courts must evaluate the nature of underlying reliance investments in assessing remedies. Since parties to a contract often have better information about the nature of specific investments, it will be even better to allow parties to stipulate their own contract remedies. ${ }^{34}$ Finally, our irrelevance of contracting result suggests the limited value of contracting in the presence of cooperative investments. More precisely, fixedprice contracts have no value in the presence of renegotiation. This result contrasts with the selfinvestment case in which a simple fixed-price contract can restore efficiency. The limited value of contracting redirects our attention to property rights and organizational governance as important sources of investment incentives. 


\section{References}

Aghion, Philippe., Dewatripont, Mathias, and Rey, Patrick, "Renegotiation Design with

Unverifiable Information," Econometrica, 1994, 62, 257-282.

The American Law Institute. Restatement (Second) of the Law of Contracts. St. Paul, American

Law Institute Publishers, 1981.

Chung, Tai-Yeong, "Incomplete Contracts, Specific Investments, and Risk Sharing," Review of Economic Study, 1991, 58, 1031 - 1042.

, "On the Social Optimality of Liquidated Damages Clauses: An Economic

Analysis," Journal of Law, Economics \& Organization, 1992, 8, 280-305.

Cibinic, John Jr., and Nash, Ralph C., Administration of Government Contracts, Second Ed.,

Washington DC: The George Washington University, 1985.

Cooter, Robert, "Unity in Tort, Contract, and Property: The Model of Precaution," 1985, 73, 151.

Edlin, Aaron S., "Cadillac Contracts and Up-Front Payments: Efficient Investment under Expectation Damages," Journal of Law, Economics and Organization, 1996, 12, 98-118. and Reicheistein, Stefan, "Holdups, Standard Breach Remedies, and Optimal

Investment", American Economic Review, 1996, 86, 478-501

Grossman, Sanford J. and Hart, Oliver D., "Costs and Benefits of Ownership: A Theory of Vertical and Lateral Integration," Journal of Political Economy, 1986, 94, 691- 719.

Hart, Oliver D. and Holmstrom, Bengt, "Theory of Contracts," in Truman F. Bewley, ed., Advances in Economic Theory: Fifth World Congress, Cambridge: Cambridge University Press, 1987, pp. 71-155. 
and Moore, John, "Incomplete Contracts and Renegotiation," Econometrica,

$1988,56,755-85$.

and , "Property Rights and the Nature of the Firm," Journal of Political

Economy, 1990, 98, 1119-1158.

Hermalin, Benjamin E. and Katz, Michael L., "Judicial Modification of Contracts between Sophisticated Parties: A More Complete View of Incomplete Contracts and Their Breach," Journal of Law, Economics and Organization, 1993, 9, 230-255.

Holmstrom, Bengt, "Moral Hazard in Teams," Bell Journal of Economics, 1982, 13, 324-40. and Milgrom. Paul. "Aggregation and Linearity in the Provision of Intertemporal Incentives," Econometrica, 1987, 55, 303-328. and "Multitask Principal-Agent Analyses: Incentive Contracts, Asset Ownership, and Job Design," Journal of Law, Economics and Organization, 1991, 7, 24-52.

Kahn, Charles, and Huberman, Gur, "Two-sided Uncertainty and 'Up-or-Out' Contracts," Journal of Labor Economics, 1988, 6, 423-444.

Konakayama, Akira, Toshihide Mitsui, and Shinichi Wanatabe, "Efficient Contracting with Reliance and a Damage Measure," Rand Journal of Economics, 1986, 17, 450-457.

Lichtenberg, Frank, "The Private R\&D Investment Response to Federal Design and Technical Competitions," American Economic Review, 1988, 78, 550-59.

MacLeod, W. Bentley and Malcomson, James M.. "Investments, Holdup, and the Form of Market Contracts," American Economic Review, 1993, 83, 811-837.

Nash, Ralph C., and Cibinic, John Jr., Federal Procurement Law, Volume II Contract Performance, Third Ed., Washington DC: The George Washington University, 1980. 
Nöldeke, George and Schmidt, Klaus M., "Option Contracts and Renegotiation: A Solution to the hold-up problem," RAND Journai of Economics, 1995, 26, 163-179.

Perlman, Matthew and Goodrich, William Jr., "Termination for Convenience Settlement - The Government's Limited Payment for Cancellation of Contracts," Public Contract Law Journal, 1978, 10, 1-52.

Rogerson, William P., "Efficient Reliance and Damages Measures for Breach of Contract," Rand Journal of Economics, 1984, 15, 39-53.

, "Profit Regulation of Defense Contractors and Prizes for Innovation," Journal of Political Economy, 1989, 97, 1284-1305.

, "Contractual Solutions to the Hold-Up Problem," Review of Economic Studies, 1992, 59, 777-793.

, "Economic Incentives and the Defense Procurement Process," Journal of Economic Perspectives, 1994, 8, 65-90.

Shavell, Steven, "Damages measures for Breach of Contract," Bell Journal of Economics, 1980, $11,466-490$.

_ "The Design of Contracts and Remedies for Breach," Quarterly Journal of Economics, 1984, 121-147.

Spier, Kathryn and Whinston, Michael, "On the Efficiency of Privately Stipulated Damages for Breach of Contract: Entry Barriers, Reliance, and Renegotiation," Rand Journal of Economics, 1995, 26, 180-202.

Taylor, Curtis R., "Delivery-contingent Contracts for Research," Journal of Law, Economics and Organization, 1993, 9, 188-203. 
Tirole, Jean, "Procurement and Renegotiation." Journal of Political Economy, 1986, 94, 235259.

Williamson, Oliver, The Economic Institutions of Capitalism. New York: The Free Press, 1985. 


\section{Appendix}

Here, we examine the conditions under which our results are extended to multidimensional cooperative investments. We suppose that the seller makes investments in $\mathrm{n} \geq 2$ different activities which can increase (stochastically) the buyer's valuation of the seller's performance. Again, the investments yield no direct return to the seller.

Our formal model is the same as before except for the part pertaining to the investments. Let $I=\left(I_{1}, \ldots, I_{n}\right) \in \Re_{+}^{n}$ denote a vector of investments that the seller makes. These investments are measured in the monetary unit. The buyer's benefit from the seller's performance, $\mathrm{v}$, is drawn from $[0, V]$ by the distribution function, $G(\cdot \mid I)$. Assumptions 1,2 and 3 are now replaced by the following assumptions.

Assumption A1. G is twice continuously differentiable in $(\mathrm{v}, \mathrm{I})$,

Assumption A2. $\quad \mathrm{G}(\mathrm{v} \mid \mathrm{I})$ is strictly decreasing and convex in $I \in \Re_{+}^{\mathrm{n}}$, for all $\mathrm{v}$ in $(0, \mathrm{~V}) .^{35}$ Assumption A3. For all $\mathrm{v}$ in $(0, \mathrm{~V}), \mathrm{G}_{\mathrm{i}}(\mathrm{v} \mid \mathrm{I})=-\infty$ if $\mathrm{I}_{\mathrm{i}}=0$, and $\mathrm{G}_{\mathrm{i}}(\mathrm{vII})=0$ if $\mathrm{I}_{\mathrm{i}}=\infty$, where $G_{i}$ denotes the partial derivative of $G$ with respect to $I_{i}$.

For ease of analysis and exposition, we also assume that there exists a unique investment solution to all problems that we consider. Let $i$ denote an n-dimensional vector of 1 's, $\mathrm{P}(\mathrm{I})$ expected payment that the seller receives, and $\Omega$ the set of v's in which trade occurs. Then, the seller's expected surplus is written

$$
\mathrm{U}(\mathbf{I})=\mathrm{P}(\mathbf{I})-\mathrm{i}^{\mathrm{T}} \mathbf{I}
$$

The expected joint surplus of the buyer and seller is described as:

$$
W(I)=\rfloor_{\Omega}(v-c) d G(v \mid I)-i^{T} I
$$


The buyer's expected surplus is the difference, $\mathrm{W}(\mathbf{I})-\mathrm{U}(\mathbf{I})$.

The first-best outcome is characterized in essentially the same way as before, with the first-best investments characterized in a way analogous to (4). The contract remedies considered in the text are succinctly characterized by the net trade price, $x=p-\delta$, in the same way as before, except that now the $R D$ rule has $x=i^{T} I$.

All the first-order conditions for the seller's investment in the text readily carry over to the multi-investment environment with obvious modification (i.e., each condition now pertains to a partial derivative with respect to each investment activity). Thus, several results can be confirmed without any analysis. For example, the ED rule still provides no investment incentive. Also, the optimal fixed-price contract with privately stipulated damages outperforms the ED rule and sets the net trade price strictly above c. Therefore, Propositions 1, 2, 4 and 5 hold.

With a stronger assumption, all other theorems can be shown to hold as well. Instead of Assumptions $\mathrm{A} 1, \mathrm{~A} 2$ and $\mathrm{A} 3$, consider the following assumption:

Assumption A4. There exists an increasing function, $\eta: \Re_{+}^{\mathfrak{n}} \rightarrow \Re_{+}$, such that $\mathrm{G}(\mathrm{v} \mid \mathbf{I}) \equiv \mathrm{F}(\mathrm{v} \ln (\mathbf{I}))$, where $F(\cdot \mid e)$ satisfies Assumptions 1, 2 and 3.

The key element of the assumption is that the stochastic ordering between different investment mixes remain invariant over $(0, \mathrm{~V})$, which seems not so unreasonable.

Now define the smallest cost of attaining $e=\eta(\mathbf{I})$,

$$
C(e) \equiv \inf _{I}\left\{{ }^{\mathrm{T}} \mathrm{I} \text { s.t. } \mathrm{e}=\eta(\mathrm{I})\right\} \text {. }
$$

The problem is thus reduced to that of a single dimensional investment, where the seller chooses e to maximize her expected surplus. All the results of the paper then hold, with e regarded as a single investment choice. 


\section{Notes}

1 This statement was originally made by Oliver Williamson (1985) and was subsequently shown formally by Hart and Moore (1988) and Tirole (1986).

2 The existing literature proposes solutions to the holdup problem that involve asset ownership structures (Grossman and Hart (1986), and Hart and Moore (1990)), legal rules of remedies (Shavell (1980) and Rogerson (1984), and various incomplete contracting schemes (Chung (1991), Aghion, Dewatripont, and Rey (1994), Edlin and Reichelstein (1996), Hermalin and Katz (1993), Rogerson (1992) and Nöldeke and Schmidt (1995)).

${ }^{3}$ Hart and Holmstrom (1987) and MacLeod and Malcomson (1993) consider cases involving such investments. The former recognizes the difficulty of inducing the investments, while the latter suggests a contractual arrangement that specifies the circumstances under which parties exercise their outside options. Our approach is distinguished by not allowing such an arrangement. See also endnote 9.

+ Hart and Holmstrom (1987, p. 135) provide another example: An electricity generating plant is a buyer and a coal mine that the plant site is next to is a seller. The coal supplier chooses the type of mine to be developed. By developing a good seam, the mine may raise the quality of coal supplied. On the other hand, the plant chooses the type of coal-burning boiler to be installed. By investing in a better boiler, the power plant may be able to burn lower quality coal, thus reducing the seller's costs.

5 This contracting environment resembles that of the principal-agent literature (see Holmstrom (1979) and Grossman and Hart (1983), for example). Our model differs from a typical principalagent model in that the gains from trade, while observable, are not verifiable here, so the sharing 
contract considered in the principal-agent literature is not feasible. In addition, investment is observable (while not verifiable) in our model, so there is no hidden action problem per se. The situation is also similar to the labor contracting environment considered by Kahn and Hurberman (1988). Indeed, their "up-or-out" contract is essentially the same as the fixed-price contract that we consider in Section III.B. Our focus on contract remedies as well as the possibility of renegotiation differentiates the current paper.

${ }^{6}$ The expectation damages rule compensates, in monetary terms, a loss that occurs to a party when his trading partner breaches a contract. The reliance damages rule compensates a party's out-of-pocket expenses in the event that his partner breaches the contract.

7 This bargaining outcome can be justified as a generalized Nash bargaining solution or alternatively as an equilibrium outcome of the alternating bargaining game where the seller and the buyer are given an opportunity to start an offer with probability $\alpha$ and $1-\alpha$, respectively. See MacLeod and Malcomson (1993) for a similar justification.

${ }^{8}$ Even when investments are partially contractible, it is still difficult to induce efficient cooperative investment. Suppose that the total amount of investments is verifiable but that the expenditure on a cooperative investment cannot be disentangled from that on a self investment. Then, the parties can write a forcing contract that mandates the seller to invest at the (aggregate) level of I. Even with such a contract, the seller will make zero cooperative investment, as long as $\mathrm{c}^{\prime}(\mathrm{I})<0$.

${ }^{9}$ MacLeod and Malcomson (1993) allow a richer contract design which specifies two different no-trade prices, distinguished by whether the breaching party subsequently trades with a third party. Such an arrangement requires a court to verify the motive of breach, which is often very 
difficult since a party can engage in a spurious trade with a third party if it turns out to be profitable.

${ }^{10}$ If the contract does not involve an upfront fee, the seller's participation in the contract will imply that $\mathrm{p} \geq \mathrm{c}$, so the seller will never breach. Alternatively, one can invoke the penalty doctrine, according to which the court enforces damages only if they do not overcompensate the victim, that is, only if $\delta \leq p-c$, or $x \geq c$. Later, we consider the so-called Cadillac contract in which the seller becomes a potential breaching party by an appropriate choice of the contract price. See endnote 14.

1 This approach is contrasted with Chung (1991) and Aghion, Dewatripont, and Rey (1994) who assume that the parties can initially specify (contractually or otherwise) their ex post bargaining power. In particular, Aghion, Dewatripont and Rey consider an elaborate scheme involving bonding, as a way to control the "patience" of parties, or their bargaining positions. Such a scheme may be subject to a renegotiation, upon one party's protest, and may not be easy to implement.

12 The ED rule intends to protect the victim's (the seller's in this model) expectation interest, which is his interest in having the benefit of the bargain by being put in as good a position as he would have been in had the contract been performed (Restatement (Second) of Contracts § 344). ${ }^{13}$ The same result holds also for self investments. See Shavell (1980).

${ }^{14}$ This result is not changed with a Cadillac contract in which the identity of a breaching party is changed by an appropriate design of the contract (see Edlin [1996]). Suppose that $\mathrm{p}=0$ so that $\mathrm{v}$ - $p \geq 0$ for all $v$. The parties can arrange an up-front transfer payment in line with their initial bargaining power so that the seller has an incentive to sign the contract. With the contract price, 
the buyer never breaches provided that damages are non-negative. Thus, the seller is the only potential breaching party, who breaches if and only if $\mathrm{p}-\mathrm{c}<-\delta^{\mathrm{c}}=-(\mathrm{v}-\mathrm{p})$, where $\delta^{\mathrm{c}}$ is the expectation damages that the seller has to pay the buyer in case of a breach. Therefore, the Cadillac contract leads to an efficient trade decision. The seller now faces the expected payoff function

$$
\begin{aligned}
U E(e) & =p+\int_{\{v<c\}}[-v] d F(v l e)+\int_{\{v \geq c\}}[-c] d F(v \mid e)-e \\
& =p-c+\int_{\{v<c\}} F(v l e) d v-e
\end{aligned}
$$

where the second equality follows from integration by parts and rearrangement of terms. It is straightforward from the above payoff function that the seller's optimal choice is $e=0$. The simple intuition is that with the Cadillac contract the supplier pays $\mathrm{v}$ - $\mathrm{p}$ whenever she breaches, so reducing investment lowers his payment stochastically.

${ }_{15}$ Without more information on the distribution function, $\mathrm{F}(\bullet \bullet)$, it cannot be determined whether the optimal LD contract induces overinvestment or underinvestment relative to the first best level. The first-best investment level is not the proper benchmark, however, since the trade decision is distorted. Using the same envelope argument, it can be seen that too little investment is induced, given the (inefficient) trade decision.

${ }^{16}$ More generally, it is impossible for parties to stipulate a simple damages rule that achieves the first-best outcome unless investment is contractible, or more complex contracts are feasible. In particular, the efficient expectation damages rule, which achieves the first-best outcome in the standard setting with self investments, does not work in the presence of cooperative investments. 
${ }^{17}$ If the parties engage in an ex ante bargaining to determine the terms of contract, $\delta$ may be chosen to split their expected surplus.

${ }^{18}$ The RD rule intends to protect the victim's reliance interest, which is his interest in being reimbursed for loss caused by reliance on the contract by being put in as good a position as he would have been in had the contract not been made (Restatement (Second) of Contracts $\S 344$ ). ${ }^{19}$ Given the additional verifiable information, one may consider a different scheme such as a forcing contract, which would penalizes the investor when she does not pick the correct amount of investment. The forcing contract is not common in practice, however, for several reasons. First, the ex post verifiability of investment expenses may not imply ex ante contractibility on the investment, if the latter is difficult to describe objectively. Second, the investment may be multidimensional and each investment type may not be separately observable. In this case, a forcing contract on observed investment types can create distortion among different types, as was shown in Holmstrom and Milgrom (1991). Finally, there may be uncertainty in the measurement of the investment. Incentives under a forcing contract are often sensitive to measurement errors, so a linear contract (as in the $\mathrm{RD}$ rule) may be optimal when the surrounding uncertainty is complex, as was shown in Holmstrom and Milgrom (1987).

${ }^{20}$ The expectation damages are ordinarily awarded, and the reliance damages are awarded only in limited circumstances: Contract damages are ordinarily based on the injured party's expectation interest (Restatement (Second) of Contract § 347). The injured party may, if he chooses, ignore the element of profit and recover as damages his expenditures in reliance. He may choose to do this if he cannot prove his profit with reasonable certainty. He may also choose to do this in the case of a losing contract (Restatement (Second) of Contract § 349). In 
practice, expectation damages are much more difficult to assess than reliance damages.

Assessment of anticipated profit on unrealized transaction is not only difficult and but also susceptible to subjective interpretation of the hypothetical circumstance.

${ }^{21}$ The $\mathrm{RD}$ rule induces overinvestment (more so than the ED rule) and inefficient trade decision when renegotiation is not possible (Shavell [1980]). When renegotiation is possible, the trade decision becomes efficient, but the overinvestment problem remains and is severer than in the ED rule (Rogerson [1984]).

${ }^{22}$ The parties may choose to reimburse only a fraction of the investment expenses in the event of a breach. An example is the DoD's Independent Research and Development (IR\&D) program, whereby the DoD reimburses typically around $40 \%$ of the defense contractors' IR\&D expenditures (Lichtenberg [1988], Rogerson [1994]).

${ }^{23}$ See Federal Acquisition Regulation $\S 49.5$ and $\S 52.249$ (in Volume 48 of Code of Federal Regulations), 1992.

${ }^{24}$ The courts have fashioned a constructive termination doctrine and allowed contracting officers the benefit of the clause in limiting the contractor's recovery, even when they elect not to use the clause. See Cibinic and Nash (1985), Nash and Cibinic (1980).

${ }^{25} e^{R}(x)$ is well defined (non-empty) for all $x \geq 0$. Let $E^{R}(p)$ denote the unique maximizer of $U(e$, $p-e)$. Then, for a given $x>c$, there exists $p>c$ such that $x=p-E^{R}(p) \equiv \xi(p)$. This result holds since $\xi(p)>x$ for sufficiently large $p\left(\right.$ since $E^{R}(\bullet)$ is bounded above), $\xi(p)<x$ for $p$ sufficiently close to $c$, and $\xi(p)$ is continuous (since $E^{R}(p)$ is continuous by Berge's theorem of maxima). Clearly, $E^{R}(p)$ at such $p$ must satisfy (15). Thus, $E^{R}(p) \in e^{R}(x)$ for such $p$. Note that $e^{R}(x)$ may not be a singleton, since there may be more than one $p$ such that $E^{R}(p) \in e^{R}(x)$. 
${ }^{26}$ The former Conservative government in Canada signed a deal to buy 50 new military helicopters. The $\$ 4.8$ billion deal was canceled by the new Prime Minister Jean Chretien on the Liberal government's first day in office (National General News, November 29, 1993). A similar damages measure is being considered, though not originally specified in the contract, for the canceled privatization program for the operation of the Pearson Airport in Toronto.

${ }^{27}$ This specification differs slightly from the renegotiation specification in Rogerson (1984) who does not allow the buyer to make the breach decision prior to the negotiation. Our specification seems to fit better with most of the renegotiation situations. All subsequent results of this paper, except for contracting irrelevance (the last sentence in Proposition 5), hold under the Rogerson's specification.

${ }^{28}$ By convention, if $\alpha=0,(x-c) / \alpha=\infty$, and thus, $\hat{v}(x)=V$.

${ }^{29}$ The result follows since $U^{L}$ is supermodular in $e$ and $x$, and $e^{L}(x)$ is unique for all $x$.

${ }^{30}$ This latter situation is equivalent to that of "selling the firm to the agent" and yields the firstbest outcome. This implies that the parties can actually solve the underinvestment problem easily if they can design the initial contract so that they assign the entire bargaining power to one party, as suggested by Chung (1991) and Aghion, Dewatripont and Rey (1994). (Hart and Moore (1988) has a bargaining rule that allows one party to have the entire bargaining power.) As mentioned in Introduction, we assume that parties cannot contractually specify how the bargaining power is allocated between them.

${ }^{31}$ When $\alpha=0$, the outcome under renegotiation can be replicated by a fixed price contract without renegotiation by setting $x=c$ which is in turn dominated by the optimal LD contract in Proposition 2. 
32 The second derivative of $U^{R}(e, p-e)$ with respect to $e$,

$$
-\hat{v}^{\prime}(x)\left\{F_{v}(\hat{v}(x) l e)-\alpha F_{e}(\hat{v}(x) l e)\right\}+F_{e}(v(x) l e)-\alpha j_{\{c<v<\uparrow(x))} F_{e e}(v l e) d v
$$

is strictly less than zero by Assumption 2.

33 That there exists a unique optimal investment level for any $\mathrm{p} \geq \mathrm{c}$ does not necessarily imply that $e^{R}(x)$ is well defined. One can, however, show that $e^{R}(x)$ exists and is unique. Note that for all $x>c, U_{e}^{R}(0, x) \geq 0$ and $U_{e}^{R}(\cdot, x)<0$, and $U_{e}^{R}(\bullet, x)$ is continuous. Moreover, $U_{e e}^{R}(e, x)<0$.

Therefore, $e^{R}(x)$ exists and is unique.

${ }^{34}$ Such a damages rule designed by parties is enforceable by the courts: Except for the restrictions imposed by the rule that proscribes the fixing of penalties, parties are free to vary the rules governing damages, subject to the usual limitations on private agreement such as that on unconscionable contracts or terms (Restatements (Second) of Contracts, Ch. 16, p. 109).

${ }^{35}$ Vector inequality is defined in a conventional way. That is, if $\mathbf{I}>\mathbf{I}^{\prime}$, then $I_{i} \geq I_{i}{ }^{\prime}$ for all $i=1, \ldots$, $n$, and $I_{k}>I_{k}^{\prime}$ for some $k$. 


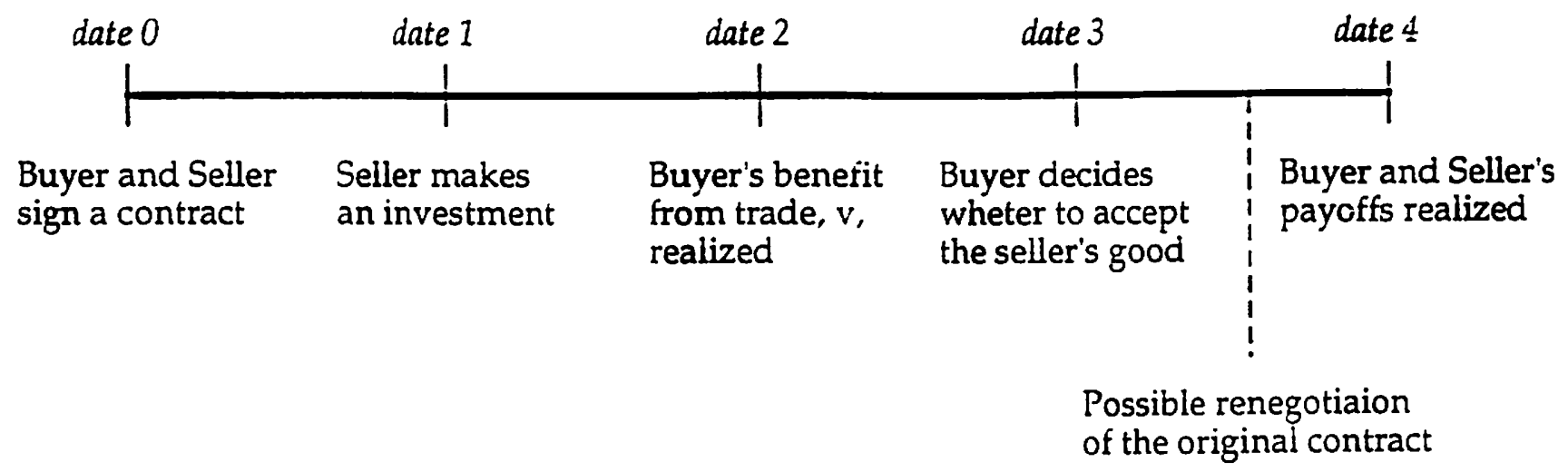

Figure 1 